Short Communication

\title{
Audit of buying patterns of drugs from various pharmacies in Northern India
}

\author{
Shalini Chawla*, Monika Agarwal, Ayush Arora
}

Department of Pharmacology, Maulana Azad Medical College, New Delhi, India

Received: 5 February 2013

Accepted: 4 April 2013

*Correspondence to:

Dr. Shalini Chawla,

Email:

drshalinichawla@hotmail.com

(C) 2013 Chawla $\mathrm{S}$ et al. This is an open-access article

distributed under the terms of the Creative Commons

Attribution License, which

permits unrestricted use,

distribution, and reproduction in any medium, provided the

original work is properly cited.

\begin{abstract}
A study was conducted to gather data regarding drug buying practices in Delhi to compare the same in rural pharmacies in surrounding area. A cross sectional study was conducted as exit interviews using pretested Performa with customers visiting randomly selected pharmacies of Delhi and rural Haryana. Out of 280 consumers interviewed 140 belonged to urban areas and 140 to rural areas. In both areas male and younger consumers are significantly high. Most consumers in both set ups took medication after physician's prescription in comparison to self medication. Source of information for self medication was media in urban and friends in rural areas. Alteration in brand name was more in rural areas. Antimicrobials and NSAIDs in rural areas and drugs for cardiovascular diseases and oral hypoglycemic drugs in urban areas are major purchased drug groups.
\end{abstract}

Keywords: Pharmacy, Urban, Rural, Consumers, Self medication

\section{INTRODUCTION}

In the recent years there has been an increasing trend towards self-medication with non-prescription drugs [sometimes referred to as over-the-counter (OTC) medicines]. ${ }^{1}$ Self medication is defined as the use of medication by a patient on his own initiative or on the advice of a pharmacist or a lay person instead of consulting a medical practitioner. ${ }^{2}$ It has its own advantages for healthcare system as it makes use of clinical skills of pharmacists, increases access to medication and may contribute to reducing expenditure on drug treatment. ${ }^{3}$ On the contrary, the use of such products may delay or mask the diagnosis of serious illness, ${ }^{4}$ with increased risks of drug interactions, adverse reactions and medication errors. ${ }^{5}$ It also increases the risk for misuse and abuse of such products. ${ }^{6}$

The phrase 'Over The Counter' drug has no legal recognition and is referred to as 'non-prescription drugs' and/or as 'household remedy'. We don't have adequate information about the exact extent of over the counter drug buying in India. The present study has been designed to generate some data regarding the drug buying practices in Delhi to compare the same in rural pharmacies in surrounding area.

\section{METHODS}

It is a cross sectional study conducted as exit interviews with customers at randomly selected pharmacies across New Delhi as Lok Nayak and GB Pant Hospitals, Connaught Place, Rohini, Safdarjung Hospital and some rural areas of Haryana as Kalanaur, Kharak, Dinod. Bamla and other villages related to Bhiwani and Rohtak districts from June - August 2010. The consumers visiting to these pharmacies were subjected to a pretested performa that had a set of questions relating to the demographic profile of the consumers, classification of the drugs purchased, whether drug was purchased on doctor's prescription or self medication, any change in terms of brand name or composition of the drugs purchased from those written in the prescription. Out of the bought medicines previous experience with those taken earlier.

Information collected was compiled and analysed with the help of Microsoft Excel and results were presented in proportions. Chi square test was used to find out 
difference between variables given in proportions and accepted statistically significant at less than 5\% error.

\section{RESULTS}

Demographic profile: Out of 280 consumers interviewed 140 belonged to urban areas and 140 to rural areas. In both areas male consumers are significantly higher than female consumers $(\mathrm{p}=0.01)$. Younger consumers are higher in both set up but more in rural areas in comparison to urban areas $(\mathrm{p}<0.001)$.

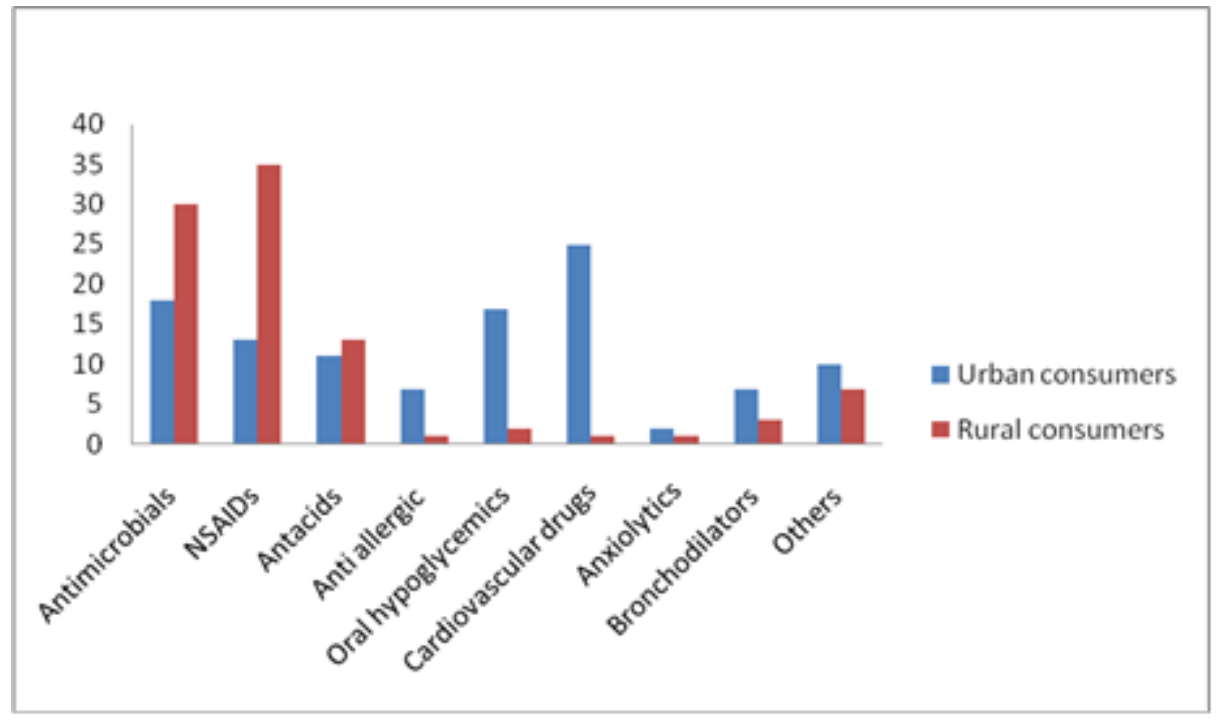

Figure 1: Distribution of drugs purchased.

Table 1: Prescription characteristics.

\begin{tabular}{|c|c|c|c|c|}
\hline & Urban & Rural & $\mathbf{X}^{2}$ & $p$ value \\
\hline Doctor prescription & $100(71.4 \%)$ & $80(57.1 \%)$ & \multirow[t]{2}{*}{6.2} & \multirow[t]{2}{*}{$<0.01$} \\
\hline Self medication & $40(38.6 \%)$ & $60(42.9 \%)$ & & \\
\hline $\begin{array}{l}\text { Self medication } \\
\text { Pharmacist assistance } \\
\text { Others }\end{array}$ & $\begin{array}{l}8(20 \%) \\
32(80 \%)\end{array}$ & $\begin{array}{l}15(25 \%) \\
45(75 \%)\end{array}$ & 0.34 & 0.56 \\
\hline \multicolumn{5}{|c|}{$\begin{array}{l}\text { Others } \\
\text { (Sources of information for self medication other } \\
\text { than pharmacist ) }\end{array}$} \\
\hline $\begin{array}{l}\text { Newspaper/internet/television } \\
\text { Friends / family }\end{array}$ & $\begin{array}{l}23(72 \%) \\
9(28 \%)\end{array}$ & $\begin{array}{l}10(22.2 \%) \\
35(77.8 \%)\end{array}$ & 18.83 & $<0.001$ \\
\hline \multicolumn{5}{|l|}{$\begin{array}{l}\text { Alteration in the drug demanded and drug } \\
\text { purchased }\end{array}$} \\
\hline $\begin{array}{l}\text { Brand name } \\
\text { Composition } \\
\text { No change }\end{array}$ & $\begin{array}{l}5(3.6 \%) \\
- \\
135(96.4 \%)\end{array}$ & $\begin{array}{l}31(22.1 \%) \\
4(2.9 \%) \\
105(75 \%)\end{array}$ & 26.25 & $<0.001$ \\
\hline $\mathrm{H} / \mathrm{O}$ previous intake & $77(55 \%)$ & $60(42.9 \%)$ & 4.13 & $<0.04$ \\
\hline $\begin{array}{l}\text { Experience with previous usage of drug } \\
\text { Problem relieved }\end{array}$ & $75(97.4 \%)$ & $60(100 \%)$ & 5.13 & 0.02 \\
\hline
\end{tabular}


Drugs for cardiovascular problems (25\%) and oral hypoglycemic agents $(17 \%)$ are the major drugs purchased in urban areas (Figure 1).

Nonsteroidal anti-inflammatory drugs (NSAIDs) (35\%) and antimicrobials $(30 \%)$ are the major classes of drugs purchased in rural areas (Figure 1).

Out of total 280 prescriptions, in both urban and rural areas $180(64.3 \%)$ in both the areas is as per doctor's prescription in comparison to $100(35.7 \%)$ from both areas which mainly on the basis of self medication (Table 1). It was observed that in both urban and rural pharmacies more drugs were purchased on the basis of doctor's prescriptions $100(71.4 \%)$ and $80(57.1 \%)$ respectively in two groups while the difference between urban and rural pharmacies was statistically significant $(\mathrm{p}<0.01)$.

Sources of self medication were mainly pharmacist assistance \& others like friend, relatives, advertisement in newspaper, T.V, internet. There is no statistical significant difference $(p=0.56)$ in term of reasons of self medication in both urban and rural areas.

Though it was observed that the drug information for self medication from media sources was $23(73 \%)$ significantly higher $(\mathrm{p}<0.001)$ in urban consumers when compared to rural consumers where family and friends 35 (77.8\%) were main source of information after pharmacist.

In urban areas alteration in the brand names was only in 5 (3.6\%) in comparison to rural area where it was significantly higher $(\mathrm{p}<.001)$, i.e. $35(25 \%)$.

\section{Experience of previous usage of drugs purchased}

Experience with previous usage was $77(55 \%)$ and 60 $(42.9 \%)$ in the urban and rural groups respectively, this difference was statistically significant $(p<0.04)$, in contrast with the previous usage the relief of problem was more in rural group and it was statistically significant $(\mathrm{p}=0.02$, Table 1$)$.

\section{DISCUSSION}

The present study divided the consumers in urban and rural backgrounds. They were interviewed for usage of prescription and non prescription drugs. In case of non prescription drugs: the most common influencing factor, relative fraction of different categories of drugs purchased like drugs for CV diseases, NSAIDS, Antimicrobials, previous history of using same drugs with its effect on their illness were noted.

In our study male consumers are significantly higher than female consumers in both urban and rural areas $(\mathrm{p}=0.01)$, it is comparable to the study conducted by PR Shankar et al in which male patients were significantly high in comparison to female patient $(\mathrm{p}<0.05)$.
In both urban as well as rural areas most patients were in the age group of 21-60 years similar to the findings of previous study conducted in Nepal. ${ }^{7}$ This shows that this age group is the most active and cautious about seeking medications for their illnesses which is easily evident from the fact that this age group is more productive. Results of our study also reflected that consumers of $>61$ years were more from urban areas as compared to rural areas which show more enlightened population of urban areas about health facilities.

Comparing the buying pattern of consumers in both rural and urban areas, it was found that antimicrobials, NSAIDs and antacids are the major groups of drugs purchased in rural areas, whereas in urban areas drugs for cardiovascular diseases and oral hypoglycemic drugs constituted more commonly sold drugs. In a similar study conducted in Chile, the most common group of medications was NSAIDs $(33 \%) .{ }^{8}$ Further in a study conducted in Australia, analgesics were the most common class of over the counter drugs (5.4 to $8.8 \%){ }^{9}$

Most consumers in both set ups took medication after physician's prescription in comparison to self medication $(\mathrm{p}<0.01)$. In self medication we included mainly pharmacist assistance and other sources like friends, drug advertisement in newspaper, TV and internet. We observed that self medication was not significantly differ in both the groups $(\mathrm{p}=0.56)$. However, prescriptions by pharmacists are more in rural areas, this shows that rural consumers either avoid visiting hospitals or there is paucity of doctors.

On observing the details of self medications it was found that source of self medication for urban population was either newspaper or internet $(70 \%)$ in comparison to rural population where friends were the main medium of information (73.3\%), reflecting more literate and technical sound urban consumers.

Alteration in brand names of drug purchased was more common in rural areas $22.1 \%$ as compared to urban areas $3.6 \%$. This can be due to more drugs are available in urban areas and urban population is more literate.

Examination of previous usage of drug revealed that $45 \%$ of urban and $57.1 \%$ rural consumers had never taken medication.

The present study emphasize the need for proper education and training to medical students regarding need for rational prescribing, physician should do judicious prescribing while there is also an urgent need for legal measures to restrict the over the counter purchase of drugs so that pharmacist can dispense drugs only on prescriptions. These multipronged measures should ensure less medical errors and rationalize drug therapy by improving prescribing patterns. 
Funding: No funding sources

Conflict of interest: None declared

Ethical approval: Not required

\section{REFERENCES}

1. Wazaify M, Shields E, Hughes CM, McElnay JC. Societal perspectives on over-the-counter (OTC) medicines. Fam Pract 2005;22:170-6.

2. WHO guidelines for the regulatory assessment of medicinal products for use in self medication, 2000. Available at www.who.int/medicines/library/qsm/whoedm-qsm2000-1/who-edm-qsm-00_1.htm.

3. Hughes CM, McElnay JC, Fleming GF. Benefits and risks of self medication. Drug Saf 2001;24:1027-37.

4. Hughes C. Monitoring self-medication. Expert Opin Drug Saf 2003;2:1-5.
5. Bradley $\mathrm{CP}$, Bond $\mathrm{C}$. Increasing the number of drugs available over the counter: arguments for and against. Br J Gen Pract 1995;45:553-6.

6. Hughes GF, McElnay JC, Hughes CM, McKenna P. Abuse/misuse of non-prescription drugs. Pharm World Sci 1999;21:251-5.

7. Shankar PR, Partha P, Shenoy N. Self medication and nondoctor prescription practices in Pokhara Valley, Western Nepal: a questionnaire-based study. BMC Fam Pract 2002;3:17.

8. Fuentes Albarrán K, Villa Zapata L. Analysis and quantification of self-medication patterns of customers in community pharmacies in southern Chile. Pharm World Sci 2008;30:863-8.

9. Goh LY, Vitry AI, Semple SJ, Esterman A, Luszcz MA. Self-medication with over-the-counter drugs and complementary medications in South Australia's elderly population. BMC Complement Altern Med 2009;9:42.

doi:10.5455/2319-2003.ijbcp20130618

Cite this article as: Chawla S, Agarwal M, Arora A.

Audit of buying patterns of drugs from various pharmacies in Northern India. Int J Basic Clin Pharmacol 2013;2:326-9. 